\title{
A Comparative evaluation of Non-descent vaginal hysterectomy versus Total Abdominal hysterectomy: A hospital based case control study
}

\begin{abstract}
$\mathrm{BCD}^{1}$, Sharma $\mathrm{A}^{2}$, Mahaseth $\mathrm{BK}^{3}$, Sharma $\mathrm{N}^{4}$
\section{ABSTRACT}

Background: Hysterectomy is a common surgery performed by gynecologist worldwide. It can be done either by vaginal, abdominal or laparoscopic route. Non decent vaginal hysterectomy (NDVH) is less invasive, less time consuming and scar less surgery. The blood loss during surgery, intra-operative and post-operative complications are less in NDVH compare to TAH (total abdominal hysterectomy). Aim and objective: to compare the clinical outcome between NDVH and TAH. Method: A hospital based prospective study was done at Nepalgunj medical collage Kolhapur between March 2018-March 2019, 60 cases fulfilling selection criteria were selected , 30 cases underwent NDVH next 30 cases underwent TAH. Outcome is measured on the basis of operating time, blood loss during surgery, hospital stay and post-operative complications. Result: The most common indication for hysterectomy was fibroid uterus in both the groups (NDVH and TAH). The operating time, blood loss, hospital stay and post-operative complications were less in NDVH as compare to TAH. Conclusion: NDVH is a choice of surgery over TAH for freely mobile uterus with benign pathology and uterus size less than twelve weeks and without adenexal pathology.
\end{abstract}

Keyword: Non decent vaginal hysterectomy (NDVH), Total abdominal hysterectomy (TAH).

\section{INTRODUCTION}

Hysterectomy is one of the major gynecological surgeries performed worldwide. It can be performed either by vaginal, abdominal or laparoscopic routes.

Non descent vaginal hysterectomy is less invasive scar-less hysterectomy for non-descended uterus done for benign pathology of like fibroid uterus, DUB and adenomyosis with uterus size less than 12 weeks and mobile uterus. The operative time is less, postoperative comfort is better, hospital stay is less, blood loss during surgery is minimal, and chances of surgical site infection are also minimal.

There are certain limitations of NDVH like difficult to perform in uterus size $>12 \mathrm{wks}$, (Bisection, Myomectomy, and Morsellation) can be done in big sized uterus. The uterus should be freely mobile with absence of adnexal pathology and it is difficult to perform in scared uterus. It increases the complication.

1. Dr. Durga BC

2. Dr. Aseem Sharma

3. Dr. Binod Mahaseth

4. Dr. Nirmala Sharma

\section{Address for correspondence:}

Dr.Durga BC

Lecturer

Department of Obstetrics and Gynaecology

Nepalgunj Medical College \& Teaching Hospital

Kohalpur, Banke, Nepal

977-9851258287

E-mail:durgabc53@gmail.com
Abdominal hysterectomy gives better operative field vision, can be performed in uterus size $>12$ weeks and uterus with adnexal pathology. So, both the method has certain limitation and benefit equally, while deciding the route of hysterectomy. It depends upon the case selection and expertise on surgeon. NDVH should be performed by competent surgeon with better vaginal surgery skill.

\section{Objectives of study:}

1. To compare the outcome of the NDVH and TAH

\section{METHODS}

A hospital based prospective study carried out from March 2018- March 2019 at Nepalgunj Medical College Teaching Hospital, Kohalpur, to compare the outcome in vaginal hysterectomy for non-descended uterus (NDVH) and abdominal hysterectomy over the period of one year, 60 patient were taken, among them 30 patient underwent $\mathrm{NDVH}$ (group A) and 30 patient underwent abdominal hysterectomy (group B).

Patient requiring hysterectomy and fulfilling inclusion criteria were selected from OPD detail history, examination, investigation performed and informed consent is taken. Hysterectomy is performed either by vaginal or abdominal route. Data were collected on the basis of indication for hysterectomy, hospital stay, operating time, post-operative complications and blood loss during surgery. The blood loss during surgery is measured by weighing of pre and post surgerygauze. 


\section{Inclusion Criteria for NDVH or TAH}

Uterus sizes less than 12 weeks

Freely mobile uterus without adnexal pathology

Non-scared uterus

Non descended uterus

\section{RESULTS}

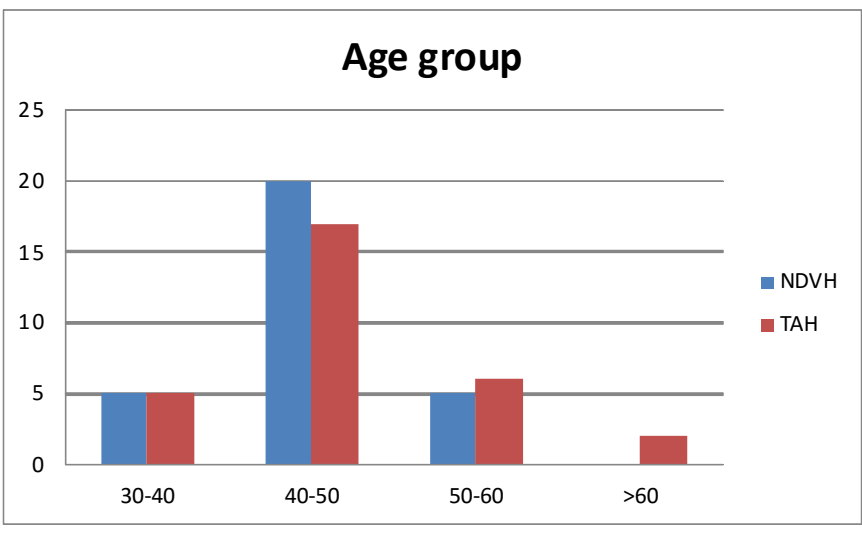

Fig 1: Distribution according to the age group

The maximum hysterectomies either through vaginal or abdominal route has been performed in ladies in between age of 40-50 yrs, standard deviation is (0.069) and least number of hysterectomies has been performed after age of sixty which is common for both the group. (fig.1)

\begin{tabular}{|c|c|c|c|c|}
\hline \multirow[t]{2}{*}{ Time consumed } & \multicolumn{2}{|c|}{ Route of Surgery } & \multirow[t]{2}{*}{ Total } & \multirow[t]{2}{*}{ pValue } \\
\hline & $\mathrm{NDVH}$ & TAH & & \\
\hline$<90 \mathrm{~min}$ (count/\%within & $24 /(80 \%)$ & $10 /(33.3 \%)$ & 34 & \\
\hline route of surgery) & & & & 0.000 \\
\hline $\begin{array}{l}>90 \mathrm{~min} \text { (count/\%within } \\
\text { route of surgery) }\end{array}$ & $6 /(20 \%)$ & $20 /(66.7 \%)$ & 26 & \\
\hline Total & 30 & 30 & 60 & \\
\hline
\end{tabular}

Table I : Time consumed during surgery

In our study about $80 \%$ of NDVH cases are operated within 90 minute and only $20 \%$ of cases required more than 90 minute time but $66.7 \%$ of TAH cases required more than 90 minute and only $33.3 \%$ of TAH cases were operated within 90 minute .This study shows that operating time in NDVH is less than in $\mathrm{TAH}$. Data are statically significant hence $p$ Value is 0.000 . (Table I)

\begin{tabular}{|l|l|l|l|l|}
\hline \multirow{2}{*}{$\begin{array}{l}\text { Blood loss during } \\
\text { surgery }\end{array}$} & \multicolumn{2}{|c|}{ Route of surgery } & \multirow{2}{*}{ Total } & \multirow{2}{*}{ P value } \\
\cline { 2 - 4 } & NDVH & TAH & & \\
\hline $\begin{array}{l}<200 \mathrm{ml} \text { (\% within } \\
\text { surgery route) }\end{array}$ & $19(63.3 \%)$ & $7(23.3 \%)$ & $26(43.3 \%)$ & \\
\hline $\begin{array}{l}>200 \mathrm{ml}(\% \text { within } \\
\text { surgery route) }\end{array}$ & $11(36.7 \%)$ & $23(76.7 \%)$ & $34(56.7 \%)$ & \\
\hline Total & $30(100 \%)$ & $30(100 \%)$ & $60(100 \%)$ & \\
\hline
\end{tabular}

Table II: Estimation of blood loss during surgery

Our study shows that blood loss during NDVH is less as compare to TAH which is statically significant. (Table II)

\begin{tabular}{|c|c|c|c|c|}
\hline Duration of & \multicolumn{2}{|c|}{ Route of surgery } & Total & P Value \\
\hline hospital stay & NDVH & TAH & & \\
\hline$<5$ days & $27(90 \%)$ & $0(0 \%)$ & 27 & 0.000 \\
\hline 5-7 days & $3(10 \%)$ & $24(80 \%)$ & 27 & \\
\hline$>7$ days & $0(0 \%)$ & $6(20 \%)$ & 60 & \\
\hline Total & 30 & 30 & 60 & \\
\hline
\end{tabular}

Table III: Distribution according to duration of hospital stay

The duration of hospital stay in NDVH group is less as compared with TAH group, maximum cases (90\%) following NDVH were discharged with 5 days following surgery but patients who underwent TAH had longer hospital stay about $80 \%$ cases stayed till 7 days postoperative and about $20 \%$ cases even stayed more than 7 days which is statically significant $p$ value (0.000). (Table III)

\begin{tabular}{llcc}
\hline \multicolumn{1}{c}{ COMPLICATIONS } & \multicolumn{2}{l}{ ROUTE OF SURGERY } & Total \\
\cline { 2 - 4 } (Count and \% within complications) & NDVH & TAH & \\
\cline { 2 - 4 } No complication & $21(70 \%)$ & $13(43.4 \%)$ & 34 \\
UTI & $5(16.6 \%)$ & $5(16.6 \%)$ & 10 \\
Vault infection & $2(6.7 \%)$ & $0(0 \%)$ & 2 \\
\hline Fever & $2(6.7 \%)$ & $8(26.7 \%)$ & 10 \\
& & & \\
\hline
\end{tabular}

Table IV: Complications of surgery 
In our study out of 60 cases 34 cases had no complication UTI is common in both group, i.e. $16.6 \%$. Wound infection (13.3\%) and postoperative fever $(26.7 \%)$ is more in those cases who underwent TAH. (Table IV)

\section{DISCUSSION}

This is the era of non-invasive surgery so NDVH is becoming choice of hysterectomy for non-descended uterus with benign lesions and freely mobile uterus with size not more than 12 weeks

In our study the maximum hysterectomy either TAH or NDVH is being performed between age group of $40-50$ years. This is similar to the study conducted by L.Pranathi, Y.Madhavi ${ }^{1}$.

In our study most common indication for hysterectomy either (NDVH or TAH) is fibroid uterus followed by DUB in case of NDVH and uterus with ovarian pathology in case of TAH. This is similar to the study done by Mehta K et al ${ }^{3}$.

UTI is common complication in both NDVH and TAH and incidence is $16.6 \%$, which is similar to the study done by Goswami D et al'.

The incidence of wound infection and fever is high in TAH as compared to NDVH which is similar to the study done by Chen B,et $\mathrm{al}^{7}$.

In the study conducted by Bansal $\mathrm{N}$ et al. They reported 4 cases of vesico-vaginal fistula out of 117 patients who underwent $\mathrm{TAH}$. In our study no vesico-vaginal fistula case is reported in cases that underwent $\mathrm{TAH}^{13}$.

In our study the hospital stay in patient who underwent NDVH is less as compared to TAH which is similar to the study conducted by Mehta. Ket al $^{3}$

Intra operative blood loss in TAH is more as compared with NDVH about $63.3 \%$ of NDVH cases had blood loss less than $200 \mathrm{ml}$ and $36.7 \%$ of NDVH cases had blood loss more than 200 $\mathrm{ml}$ and about $76.3 \%$ of TAH cases had blood loss more than $200 \mathrm{ml}$. Ultimately blood loss in TAH is more which is similar to the study conducted by Mehta K et al ${ }^{3}$.

The operative time is less in NDVH cases than in TAH cases about $80 \%$ cases of NDVH were finished within ninety minutes but maximum number of TAH cases requiring more than 90 minutes time it is similar with the study conducted by Goswami D et al $\left.\right|^{2}$.

\section{CONCLUSION}

From our study we came to the conclusion that NDVH should be the choice of surgery in those cases who fulfill the inclusion criteria like (uterine size less than twelve weeks size ,freely mobile and non-scared uterus without adenexal pathology ) because intra-operative blood loss, operating time intraoperative and post-operative complication are less as compared to TAH.

\section{REFERENCES}

1. L. Pranathi, Y. Madhavi. Comparative study of Non-decent vaginal hysterectomy with abdominal hysterectomy: a prospective randomized controlled trial study. J Obstet and Gynaecol India .2018; 5(1):77-81.

2. Goswami $D$ et al. Non-decent vaginal hysterectomy versus total abdominal hysterectomy in fibroid uterus: a comparative study in tertiary care hospital in Uttarakhand, India. Int J Reprod Contracept Obstet Gynaecol.2016 Aug; 5(8):2718-22.

3. Mehta. K et al. Comparative study of abdominal hysterectomy and vaginal hysterectomy in non-decent cases: a prospective study. Int J Reprod Contracept Obstet Gynaecol.2017; 6(4):1265-1270.

4. Patil SB et al .Non-decent vaginal hysterectomy: analysis of indications and complications. Int J Reprod Contracept Obstet Gynaecol. 2016; 5(7):2126-29.

5. Patel R, Chakarvarty N. Comparative study of laparoscopic hysterectomy versus vaginal hysterectomy .Int J Med Sci Public Health.2014; 3(3):335-7.

6. Singh A, Bansal S. Comparative study of morbidity and mortality associated with non-decent vaginal hysterectomy based on ultra-sonographic determination of uterine volume. Int Surg. 2008; 93(2):88-94.

7. Chen B, Ren DP, Li JX, Li CD. Comparison of vaginal and abdominal hysterectomy: a prospective non-randomized trial. Pak J Med Sci.2014; 30(4):875-9.

8. Ottosen C, Lingman G, Ottosen L. Three methods of hysterectomy: a randomized, prospective study of short term outcome. BJOG .2000; 107:1380-5.

9. Bharatnur S. Comparative study of abdominal versus vaginal hysterectomy in non-decent cases .J Obstet Gynaecol. 2010; 15(2):1528.

10. Shantini NF, Poolmar GK, Jayasree M, Bupathy A. Evaluation of complication of abdominal and vaginal hysterectomy. Int J Reprod Contracept Obstet Gynaecol.2012;1(1):7-11.

11. Begum S, Akhtar R, Barua S, Ferdous J. A cross sectional descriptive study on non-decent vaginal hysterectomy (NDVH). Chattagram Maa-O- Shishu Hospital Medical college journal.2014; 13(1):13.

12. Dewan R, Agarwal S, Minocha B, Sen SK.Non-decent vaginal hysterectomy: an experience. J Obstet Gynaecol India.2004; 54(4):376-8.

13. Bansal $\mathrm{N}$ et al. An audit of complication associated with hysterectomy. Elective hysterectomy at SVMCH and RC. Int. J Med Res Health Sci.2013; 2(2):147-55. 